Research Article

\title{
Wavelength Characteristic Analysis of a FBG Array Embedded in Quaternary Unconsolidated Strata during a Deep Borehole Installation
}

\author{
Dingding Zhang $\mathbb{D}^{1,2}$ Chenyang Ma, ${ }^{1}$ Yanyan Duan, ${ }^{1,3}$ Wengang Du, ${ }^{1}$ Jinxuan Liu, \\ and Jing Chai ${ }^{1,2}$ \\ ${ }^{1}$ School of Energy Engineering, Xi'an University of Science and Technology, Xi'an 710054, China \\ ${ }^{2}$ Key Laboratory of Western Mine Exploitation and Hazard Prevention, Xi'an 710054, China \\ ${ }^{3}$ China United Northwest Institute for Engineering Design and Research Co., Ltd., Xi'an 710054, China \\ Correspondence should be addressed to Dingding Zhang; zhangdd@xust.edu.cn
}

Received 18 May 2021; Revised 9 July 2021; Accepted 6 September 2021; Published 26 September 2021

Academic Editor: Marco Consales

Copyright (C) 2021 Dingding Zhang et al. This is an open access article distributed under the Creative Commons Attribution License, which permits unrestricted use, distribution, and reproduction in any medium, provided the original work is properly cited.

\begin{abstract}
Real-time monitoring of settlement and deformation within a coal mine's deep quaternary unconsolidated strata presents challenges with installation and signal analysis. This paper presents results from successfully installing a field-scale fiber Bragg grating (FBG) sensing system in a deep borehole for the purpose of achieving real-time monitoring of the settlement and deformation in a deep unconsolidated stratum. A $152 \mathrm{~m}$ deep by $133 \mathrm{~mm}$ diameter borehole was used to embed an array of 24 FBG sensors in 12 layers of gravel and clay from between $92.4 \mathrm{~m}$ and $148.7 \mathrm{~m}$ of unconsolidated quaternary strata. A wavelength bandwidth of $\pm 4.5 \mathrm{~nm}$ was used with a wavelength division multiplexing and spatial division multiplexing technique to compose a 4-by-6 sensor array. During the four stages of installation, the real-time transmission characteristics and the changes in the FBG wavelength for this sensing system were evaluated. While the FBG sensing system was stable after installation, it was clearly shown that the engineering techniques associated with both positioning and grouting influenced the mechanical properties and transmission characteristics of the system. After installation, the sensor survival rate was found to be $78.26 \%$ with a maximum FBG wavelength shift of $1.447 \mathrm{~nm}$. This field-scale installation has provided information and experience that will improve future installations of buried fiber optic sensing technology throughout the underground coal mine industry.
\end{abstract}

\section{Introduction}

With the development of the fiber optic sensing technology, the fiber Bragg grating (FBG), as an all-fiber passive sensing element with high performance, is applied to the safety monitoring in civil engineering, petroleum and chemical engineering, and national defense, to name a few applications. Fiber Bragg gratings can be embedded in composite material or structural systems or can be used for real-time monitoring of internal stress, strain, and displacement distributions of a material or structure [1-3], temperature distributions [4], and humidity distributions [5]. Research has also been conducted using laboratory tests and simulations $[6,7]$ on the transfer of fiber optic sensor strain $[8,9]$ and the fiber Bragg grating transverse effects [10]. Overall however, fiber optic sensing technology is still considered being in the experimental stage.

Stratum settlement caused by overexploitation of underground resources such as coal, groundwater, and petroleum is a serious geological problem, which threatens the safety of structures and people. In recent years, the coal production in the coalfields of east China has continually increased in locations such as Huaibei, Datun, Xuzhou, Yanzhou, Yongxia, and Huainan, which has brought significant development of the local economy. Since the 1980s, the coal mines in these areas have experienced problems of mine shaft damage 
induced by quaternary unconsolidated stratum settlement and deformation [11]. As one example, the main and auxiliary shafts of the Baodian Coal Mine were damaged in 1995, 1999, and 2002 causing the guides of shafts to become distorted. This damage directly affected the production of the coal mine.

In monitoring of stratum settlement, various groundbased and space-based methods have been applied. It should be noted that there are still challenges concerning these monitoring methods. Extensometers which provide precise and accurate measurements to an accuracy of $0.01-0.1 \mathrm{~mm}$ not only are costly but also yield only data on displacements between several predetermined depth intervals [12]. GPS, InSAR (DInSAR), and leveling methods enable large-area measurements of ground displacement differences without providing specific displacement of different rock layers. Moreover, its measurement is unstable, its precision is low, and its workload is large [13]. Since FBG has the potential to act as a sensor and be used to form a network, a fiber optic sensing method to monitor stratum settlement is proposed for building a quasidistributed fiber optic sensing network with the goal of realizing the long-term, real-time field monitoring of stratum settlement and deformation around mine shafts. This system was adopted in Jining no. 3 coal mine for accurate monitoring of the quaternary unconsolidated strata [14], and it was similarly adopted in the Baodian Coal Mine.

The FBG sensing system embedded in a borehole is the engineering basis for implementing this technology. In addition to the careful design of the monitoring system, the installation of the monitoring system must also be done with care. Protecting the system during installation is important for minimizing influences on fiber optic transmission characteristics and for reducing the effects of quaternary unconsolidated strata at depths of 100 to $240 \mathrm{~m}$. This paper presents results of analyzing the installation of a new mine safety monitoring system using the FBG-based recognition and prediction technology.

\section{Fiber Bragg Grating-Layered Stratum Subsidence Monitoring}

The FBG sensors used in this study were embedded in a borehole located near the shaft at the Baodian Coal Mine to form a stress-transferring system that consisted of the FBG sensor, the seal material, and the rock strata. Using the Bragg central wavelength readings from the FBG sensors and the strain-transferring mechanism of the surrounding medium, the stress and deformation of the quaternary unconsolidated strata is obtained. Figure 1 shows the FBGlayered stratum subsidence monitoring system, which is composed of the FBG sensors, the FBG network sensing analyzer, and the data collection and processing system. Figures 1(a) and 1(b) show the FBG sensors. The length of fiber Bragg grating is $10 \mathrm{~mm}$. The fiber Bragg grating is embedded into a Glass Fiber Reinforced Polymer (GFRP), and a cylindrical structure FBG sensor with the diameter of $8.64 \mathrm{~mm}$, length of $296 \mathrm{~mm}$, and end expander diameter of $11.6 \mathrm{~mm}$ is formed. Young's modulus of the encapsulation material is $21 \mathrm{GPa}$. The mechanical transfer of strain through the FBG from the quaternary unconsolidated strata occurs through the FBG-GFRP-sandy cement groutunconsolidated stratum mechanism that is formed. The formula of the strain transfer coefficient between FBG and unconsolidated strata is presented in the literature [8].

The FBG sensors can be multiplexed using the wavelength division multiplexing (WDM) technique to realize the quasidistribution sensor network. The multiplexed arrays of FBG sensors allow for measuring physical properties at discrete locations on a structure [15]. Figure 2 shows the principle of the FBG sensing system. The tunable laser source coupler transmits a light beam of a certain band width to the gratings. Some of the light that satisfies the requirements is reflected back to the coupler and then transmitted to the analyzer, where the change in the central wavelength is calculated. The sensing system consists of four light routes with each route having 6 FBG sensors for a total of 24 FBG sensors that include 22 strain sensors and 2 temperature sensors. Fiber Bragg grating temperature sensors are designed to eliminate the influence of temperature on strain measurement. Generally, it is worth noting that the influence of temperature can be ignored because the geothermal field is almost constant in the deep strata [16]. The fiber Bragg grating is embedded into a Glass Fiber Reinforced Polymer (GFRP) forming the GFRP-FBG (Glass Fiber Reinforced Polymer-fiber Bragg grating). Each light route is designed to have two surface channels (i.e., a double channel design). These channels are numbered from 1 to 8 , where nos. 1 and 5 are for route I, nos. 2 and 6 are for route II, nos. 3 and 7 are for route III, and nos. 4 and 8 are for route IV. The 24 FBG sensors form a wavelength division multiplexing (WDM)/space division multiplexing (SDM) mixedsensing array, with the spectral band width of neighboring sensors being greater than $9 \mathrm{~nm}$. This WDM technology is used for the FBG sensor array in each route, while the SDM technology is used between routes. The FBG sensing routes can be switched on or off with an optical switch so that the separate routes will not interfere with one another. The central wavelengths of sensors in the four FBG 5sensing arrays (FBG0101 FBG0406) are shown in Table 1.

\section{Installation of Borehole Embedded FBG Sensors}

3.1. Coal Mine Geology. The FBG sensing system was installed in the Baodian Coal Mine, which is developed with three vertical shafts and a horizontal main tunnel partitioning system. In 2003, the annual coal production of this mine was 6.4 million tons. The coal seam being mined is the no. 3 seam in the southern area of the mine and is separated into an upper seam portion (3up) and a lower seam portion (3down). In the northern area of the mine, the average thickness of the no. 3 seam is $8.76 \mathrm{~m}$, whereas the average thicknesses of the 3up and 3down seams in the southern area are $5.83 \mathrm{~m}$ and $3.46 \mathrm{~m}$, respectively. The coal seam inclines gently at angles from 2 to 13 degrees. The different strata, beginning from the surface down to the mining level, are the Quaternary, Jurassic, Permian, Carboniferous, and Ordovician. The thickness of the Quaternary strata ranges 


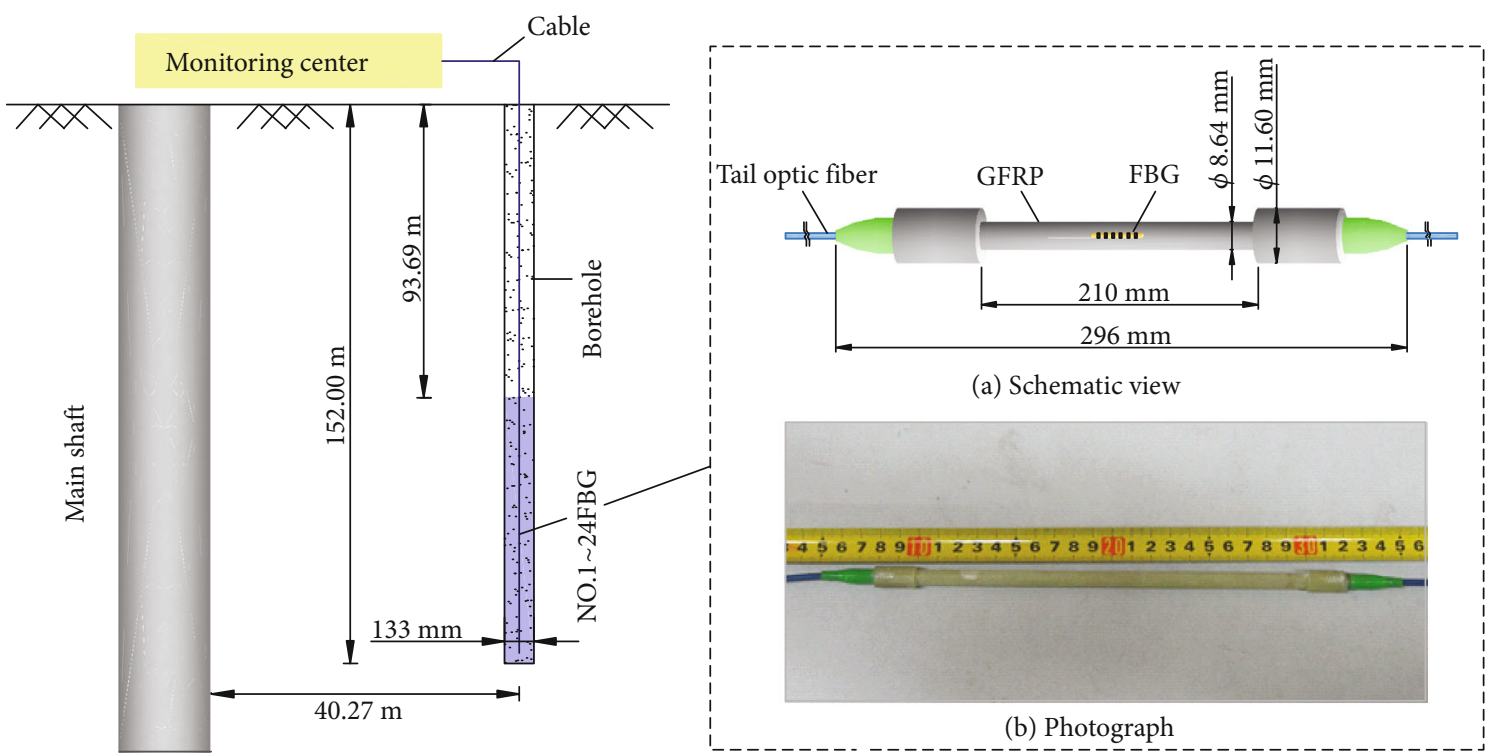

FIgURE 1: Method for monitoring the settlement in strata by optical fiber sensing.

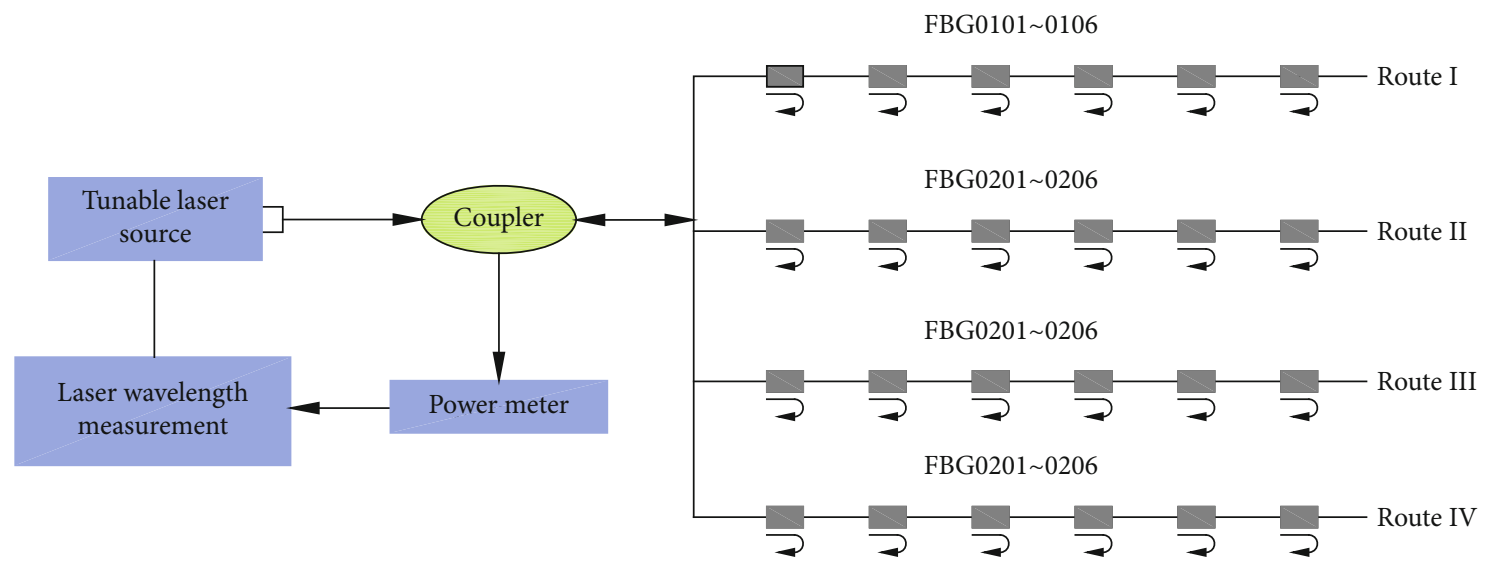

Figure 2: Principle of the FBG sensor system.

TABLE 1: Bragg central wavelength characteristics for the sensor in the four routes of the FBG sensing array.

\begin{tabular}{lcccc}
\hline $\begin{array}{l}\text { Sensor } \\
\text { number } \\
(\mathrm{xx})\end{array}$ & $\begin{array}{c}\text { Route I } \\
\text { (FBG01xx) }\end{array}$ & $\begin{array}{c}\text { Route II } \\
\text { (FBG02 xx })\end{array}$ & $\begin{array}{c}\text { Route III } \\
\text { (FBG03 xx) }\end{array}$ & $\begin{array}{c}\text { Route IV } \\
\text { FBG04 xx })\end{array}$ \\
\hline 01 & 1520.543 & 1520.593 & 1520.718 & 1520.864 \\
02 & 1528.521 & 1529.407 & 1529.648 & 1529.616 \\
03 & 1538.699 & 1538.849 & 1538.654 & 1538.633 \\
04 & 1548.836 & 1548.657 & 1548.535 & 1548.799 \\
05 & 1558.704 & 1558.221 & 1558.543 & $1558.985^{\mathrm{a}}$ \\
06 & 1568.686 & 1569.102 & $1568.989^{\mathrm{a}}$ & 1568.473 \\
\hline
\end{tabular}

${ }^{\mathrm{a}}$ FBG0306 and FBG0405 are temperature sensors.

from $110.0 \mathrm{~m}$ to $227.6 \mathrm{~m}$, with an average thickness of $170.8 \mathrm{~m}$. The Quaternary strata are thicker in the northwest and thinner in the southeast, with lenticular bodies distributed throughout. The Quaternary strata can be divided into three groups, the upper group, the middle group, and the lower group. The thickness of the upper group ranges from $50.5 \mathrm{~m}$ to $69.1 \mathrm{~m}$, with an average thickness of $57.9 \mathrm{~m}$. The upper group is composed of brown yellow clay, sandy clay, and gravely clayey sand, with the major components being sandy clay. The thickness of the middle group ranges from $50.4 \mathrm{~m}$ to $84.6 \mathrm{~m}$, with an average thickness of $66.3 \mathrm{~m}$. It is composed of sage green and brown orange clay, sandy clay, and clayey gravel. The lower group is from about 0 to $77.0 \mathrm{~m}$ in thickness, with an average thickness of $40.5 \mathrm{~m}$, and is composed of sage green, grayish yellow, and grey white clay, sandy clay, and clayey sand or gravel. The upper and lower groups are aquifer-bearing strata, while the middle group is an aquiclude.

3.2. System Installation. The observing borehole is located at a horizontal distance of $40.27 \mathrm{~m}$ to the main shaft. The distance from the lowest FBG sensor to the surface is $147.86 \mathrm{~m}$; considering that the drilling debris may fall to the bottom of the hole, which may affect the FBG to be placed in the designated place, an enough space should be 
left. The hole with a depth of $152 \mathrm{~m}$ and a diameter of $133 \mathrm{~mm}$ was finally determined. In order to prevent the borehole from collapse when drilling, it is essential to inject mud into the borehole to protect the borehole wall. The required verticality of the hole should be less than $3 \%$. Therefore, the hard alloy drilling method is used till the end of the borehole.

Based on the coal mine geology and the stratification of the quaternary unconsolidated strata, it was decided to install the FBG sensing system in the lower group of the Quaternary strata located from about $92.4 \mathrm{~m}$ to $148.7 \mathrm{~m}$ below the surface. The 24 FBG sensors were installed in 12 layers through the vertical borehole. Figure 3 shows the locations of FBG sensors and the lithology of the strata. The stratum settlement caused by groundwater loss through a waterflowing fractured zone occurred from the lower group to the upper group of the Quaternary strata during coal mining [17], so that FBG sensors were mainly arranged vertically in the middle group and lower group of Quaternary strata to monitor the vertical deformation of the strata in this case.

To assist with lowering the FBG sensor arrays into the borehole, the fiber optic cables were attached to a steel wire rope with nylon bands. During the lowered process, a $10 \mathrm{~kg}$ guide hammer was used to drag the steel wire rope down to the borehole bottom. The grouting pipe and the steel wire rope with the banded FBG system were lowered into the borehole at the same rate of $0.2 \mathrm{~m} / \mathrm{s}$. While lowering this assembly, it was important to prevent the grouting pipe from rotating in the borehole so that the assembly would not twist and cause the separation of the grouting pipe and FBG system. Once the FBG system was lowered to its predetermined position, the grouting pipe and the FBG system were separated and the steel wire rope was then attached to the grouting pipe frame so that it could be used to lift out the grouting pipe. The borehole was then sealed from the bottom to the surface by injecting cement grout into and filling the borehole while lifting up the grouting pipe. Table 2 presents grouting progress. The grouting of the borehole was divided into 4 sections, and it took 4 individual grouting steps to finish sealing the entire $152 \mathrm{~m}$ depth of the borehole. The ratio of cement, sand, and water is $1: 1: 0.5$. The cement used to seal this borehole was a $32.5 \mathrm{R}$ Portland cement. After the cement mortar is set, the compressive strength is 33.78 MPa, the elastic modulus is $7.54 \mathrm{GPa}$, and Poisson's ratio is 0.059 . The grain size of the river sand used in the cement grout was about 1.25 to $2.50 \mathrm{~mm}$. In order to avoid the FBG system from striking under excessive pressure, the slurry pump pressure was controlled between 2 to $3 \mathrm{MPa}$, and the grouting speed is controlled between 5 and $7.5 \mathrm{~m} / \mathrm{s}$.

There are four stages of installing the FBG monitoring system, these are debugging the system in the laboratory, transporting the system to the field, lowering the system into the borehole, and grouting the system into the borehole. While lowering and grouting the system into the borehole, the SM125 FBG demodulator produced by Micron Optics International Co. Ltd., America, was connected to the FBG sensor arrays. This allowed the lowering and grouting steps to be monitored in real time in anticipation of the FBG sensors experiencing deformation from influences during the grouting and the grout curing processes. Figures $3(\mathrm{a})-3(\mathrm{c})$ illustrate the configuration of various FBG monitoring system components during the process of installing it.

\section{Real-Time Monitoring Results and Analysis}

4.1. Central Wavelength Shift. The results of monitoring the wavelength shift during the various stages of the laboratory testing and debugging, the transportation to the field, the lowering of the system into the borehole, and the borehole grouting are shown in Figure 4 . The $x$-axis is the wavelength shift, and the $y$-axis is the depth. The initial wavelength was recorded in the laboratory debugging stage. The initial wavelength was subtracted from the latter data when calculating the wavelength shift of the monitoring period. After the FBG sensors were lowered into the borehole, the wavelength for almost all of the FBG sensors increased, with a maximum wavelength shift of about $0.486 \mathrm{~nm}$ occurring. Figure 4(a) shows that the wavelength shift curve is multipeak, which is mainly due to the use of nylon bands to fix the fiber optic cable to the vertical steel wire rope to share the weight of the fiber optic cable, causing reduced tensile stress of the FBG sensors near the fixed point of the nylon bands. Actually, the nylon band protection demonstrates to be effective to reduce the breakpoints in the process of lowering the fiber optic cable.

The wavelength shifts then observed after the first grouting step was about the same as the shift that occurred after the lowering of the system into the borehole, as shown in Figure 4(b). However, after the second grouting step, the wavelength shifts observed were significantly greater, with the maximum wavelength shift that occurred being about $1.447 \mathrm{~nm}$. The greatest influence on the system that was observed occurred during the second step of grouting. In order to prevent the central wavelength of FBG sensors from overlapping during the installation of the same FBG sensing array, it is suggested that the difference between the central wavelength of the two adjacent FBG sensors should be greater than $3 \mathrm{~nm}$. Overall, the FBG sensors located at shallower depths within the borehole typically exhibited a greater wavelength shift than the FBG sensors that were located deeper within the borehole. The reason for this phenomenon is that after the first grouting, the cement mortar gradually solidifies and shrinks, which makes the internal fiber optic cable tensile stress decrease, and the tensile stress in the nongrouting borehole increases at the same time.

The results from monitoring the FBG sensors' wavelength shifts during the installation process are shown in Figure 5. The $x$-axis is the time or date during the installation, and the $y$-axis is the wavelength shift. As seen in Figure 5, the wavelength shifts measured by the FBG sensors increased during the installation process but then returned to a stable condition after the installation was completed. The maximum wavelength shift observed occurred at the FBG0401 sensor located at a depth of $97.5 \mathrm{~m}$. This sensors' wavelength shift reached $1.447 \mathrm{~nm}$, which was about $32.16 \%$ below the one-way sensing range limit of $4.5 \mathrm{~nm}$, as shown in Figure 6. The wavelength then reduced to a final wavelength shift of $0.574 \mathrm{~nm}$ or rather returned to $60.33 \%$ 

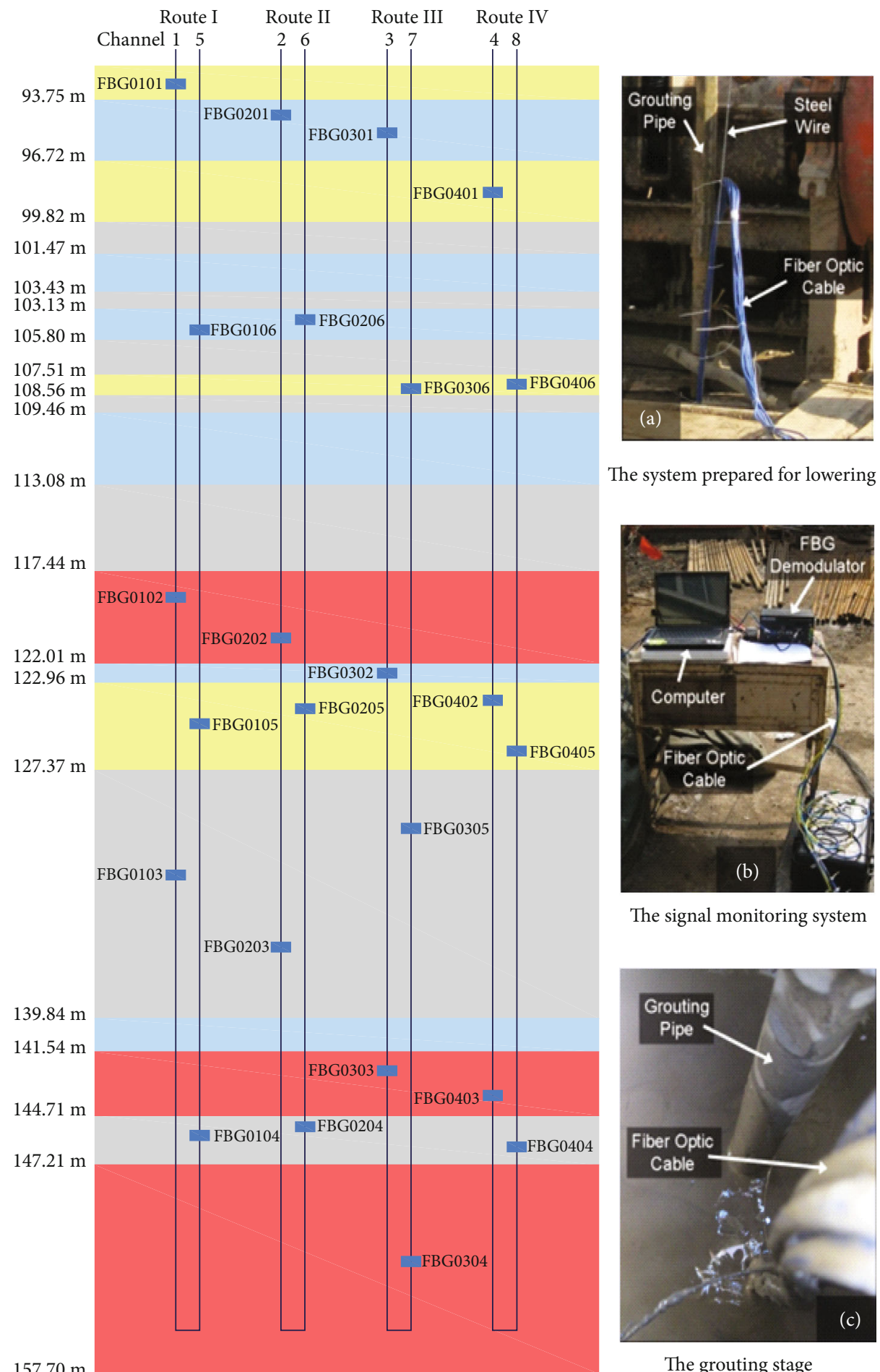

The system prepared for lowering

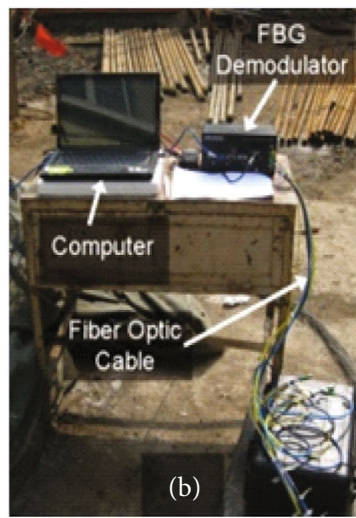

The signal monitoring system

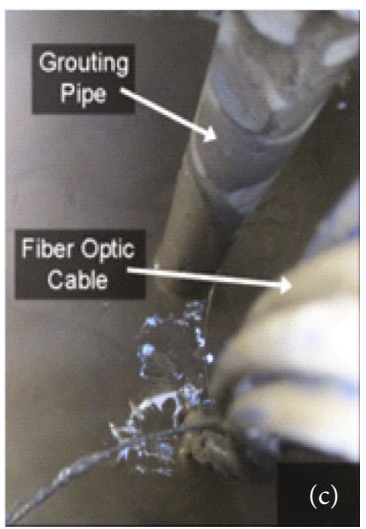

The grouting stage

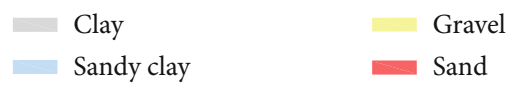

FIGURe 3: Process of installing the FBG sensor system.

below the one-way sensing range limit. The wavelength shift occurring with the FBG0301 sensor at a depth of $96.3 \mathrm{~m}$ reached a maximum of $0.881 \mathrm{~nm}$ and then reduced to a final wavelength shift of $0.149 \mathrm{~nm}$. After reaching its maximum wavelength shift, the FBG0301 sensor then returned to
$83.05 \%$ below the one-way sensing range limit. Neither of FBG0401 and FBG0301 however returned to their initial value before the installation of the system. An analysis of the fiber optical stress showed that when the wavelength shift was less than $3.0 \mathrm{~nm}$, there were no influences on the 
TABLE 2: Borehole grouting progress.

\begin{tabular}{lccc}
\hline $\begin{array}{l}\text { Grouting } \\
\text { step }\end{array}$ & $\begin{array}{c}\text { Cost time } \\
(\mathrm{min})\end{array}$ & $\begin{array}{c}\text { Grouting height } \\
(\mathrm{m})\end{array}$ & $\begin{array}{c}\text { Grouting speed } \\
(\mathrm{m} / \mathrm{s})\end{array}$ \\
\hline 1 & 2 & 15 & 7.5 \\
2 & 6 & 45 & 5 \\
3 & 7 & 95 & 7.1 \\
4 & 15 & 152 & 3.8 \\
\hline
\end{tabular}

transmission characteristics of the FBG system [18]. While the installation process affected the normal sensing range of the system to a certain degree, it did not affect the transmission characteristics of the FBG system.

4.2. Central Wavelengths of FBG Sensors. With several FBG sensors on each FBG sensor array, it becomes important to make sure that every FBG sensor can be identified. This was done by having the gratings correspond to an individual central wavelength location characteristic. In addition, the central wavelength of each grating within a given route, $\lambda 1, \lambda 2, \cdots \lambda n$, and their working range, $\Delta \lambda 1, \Delta \lambda 2, \ldots$ $\Delta \lambda n$, should not overlap with one another. The central wavelength characteristics of the FBG sensors in route I are presented in Figure 7. As can be seen, the central wavelengths for all the FBG sensors shift to the right during the installation process, which changes the value from the manufacturer's initial central wavelength factory values for the FBG sensors. The maximum wavelength shift of the FBG sensors in route I was $0.757 \mathrm{~nm}$, and the minimum wavelength shift observed was $0.002 \mathrm{~nm}$. While the wavelength shift caused by the installation represented $16.82 \%$ of the overall wavelength detection range, the design of the sensor array ensured that every FBG sensor had enough range to accommodate this amount of wavelength shift.

Different loadings or deformation conditions lead to differences in the FBG spectrum profile, not only on the Bragg wavelength [19]. Thus, it is possible to have a broader analysis of the loading condition by comparing other features of the spectrum, such as the width of FBG spectrum and reflected light power. The axial strain only leads to the wavelength shift when compared with the initial spectrum. The reason for this spectral response is the uniformity of the strain in the grating length and the absence of bendinginduced losses in this case. When torsion or bending is applied on the fiber, there is not only a wavelength shift but also an increase in the width of FBG spectrum with a reduction of the reflected light power due to the nonuniform strain distribution in the FBG region. The highest variation for torsion and bending cases when compared to the initial spectrum occurs in the grating profile and reflected light power, respectively [20]. It can be concluded from the FBG spectral characteristic curve that only the FBG central wavelength is shifted, but the width of FBG spectrum, the reflected light power, and the grating profile remain unchanged, which indicates that only vertical strain has occurred in the fiber grating sensor.
4.3. Success Rate of FBG Sensors. In Figure 8, the reflection spectra after the installation of the system are presented and demonstrate the success rate for the FBG sensors in routes III and IV. The reflection spectrum for route IV is the same as that for route III. Two interruptions occurred on route III, which led to the loss of the signal from FBG0305. In this route, channel 3 had 4 sensors remaining and channel 7 had only one sensor remaining. In route IV, the signals from FBG0402, FBG0403, FBG0404, and FBG0405 were lost, with channel 4 and channel 8 having one sensor each. Route II also had an interruption during the laboratory testing and a second interruption during the field installation, which led to the loss of the signal from FBG0206. There was only one interruption in route I. In summary, a total of 6 FBG sensors were lost, leaving 18 FBG sensors in good working condition. The overall success rate of the FBG sensor installation was $78.26 \%$, which is lower than what occurred in a previous field test.

\section{The Influence of the Transmission Characteristics}

When a beam of light enters the optic fiber, an effective reflection will be generated if the light satisfies the fiber Bragg grating requirements. The peak wavelength of the reflected light is the Bragg central wavelength. The resonance equation of the fiber Bragg grating is $\lambda_{B}=2 n_{\text {eff }} \Lambda$, where the Bragg wavelength, $\lambda_{B}$, is determined by the grating period, $\Lambda$, and the effective refractive index of the optic fiber core, $n_{\text {eff }}$. The relationship between the central wavelength of the reflected light and the strain and temperature of the gratings are

$$
\frac{\Delta \lambda_{B}}{\lambda_{B}}=\left(1-p_{e}\right) \varepsilon+(\alpha+\zeta) \Delta T,
$$

where $\lambda_{B}$ is the initial central wavelength, $\Delta \lambda_{B}$ is the wavelength shift, $\varepsilon$ and $\Delta T$ are the strain and temperature of the grating, respectively, $p_{e}$ is the effective elastic-optic coefficient, $\alpha$ is the thermal expansion coefficient, and $\zeta$ is the thermo-optic coefficient.

For the convenience of calculation, the above formula is simplified as

$$
\Delta \lambda_{B}=K_{B, \varepsilon} \varepsilon+K_{B, T} \Delta T,
$$

where $K_{B, \varepsilon}$ and $K_{B, T}$ are the strain and temperature sensitivities of the grating, respectively.

The strain sensitivity is

$$
K_{B, \varepsilon}=\lambda_{B}\left(1-p_{e}\right),
$$

where $P_{e}=0.5 n_{\text {eff }}^{2}\left[p_{12}-\mu\left(p_{11}+p_{12}\right)\right]$. For optic fibers that are made of fused quartz, Poisson's ratio is $\mu=0.16$, elastic-optic coefficients are $p_{11}=0.113$ and $p_{12}=0.252$, and the refractive index of the optic fiber core is $n_{\text {eff }}=$ 1.4682 , which results in the factor $P_{e}$ having a numerical value of $\approx 0.22$. For the silica fiber, the wavelength-strain 


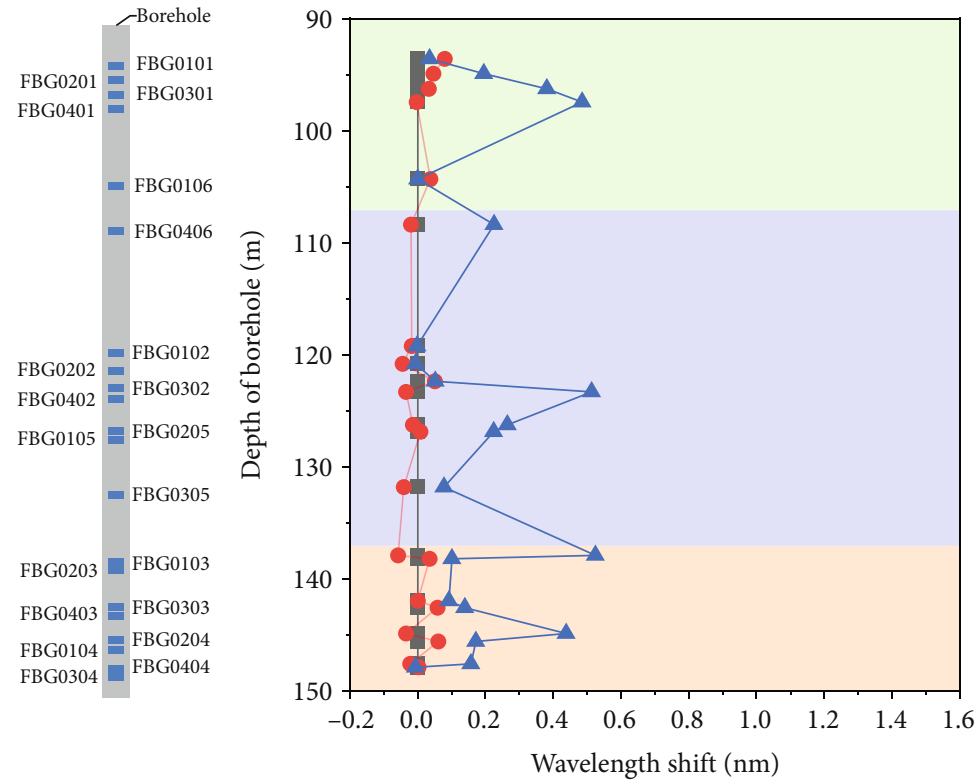

(a)

$\square$ The first grouting section
$\square$ The second grouting section
$\square$ The third grouting section
$\rightarrow-$ Debugging
-- Field
$-\_$Burying

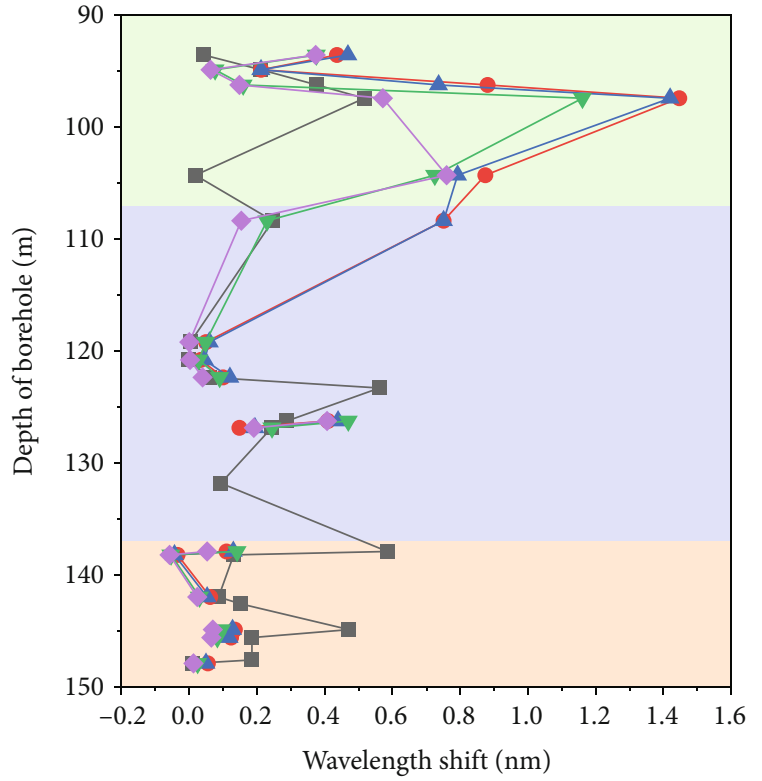

(b)

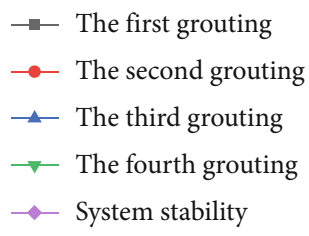

FIGURE 4: Bragg central wavelength shift of the FBG sensors at different depths during the process of installation.

sensitivities of $1.3 \mu \mathrm{m}$ and $1.55 \mu \mathrm{m}$ bare FBG sensors have been measured as $\sim 1 \mathrm{pm} / \mu \varepsilon$ and $\sim 1.15 \mathrm{pm} / \mu \varepsilon$, respectively $[21,22]$.

The temperature sensitivity is

$$
K_{B, T}=\lambda_{B}(\alpha+\zeta) \text {. }
$$

Using a quartz optic fiber mixed with germanium where $\alpha=5.5 \times 10^{-7^{\circ}} \mathrm{C}^{-1}$ and $\zeta=6.4 \times 10^{-6^{\circ}} \mathrm{C}^{-1}$. For the silica fiber, the wavelength-temperature sensitivities of $1.3 \mu \mathrm{m}$ and $1.55 \mu \mathrm{m}$ bare FBG sensors have been measured with values of $\sim 10 \mathrm{pm} /{ }^{\circ} \mathrm{C}$ and $\sim 13 \mathrm{pm} /{ }^{\circ} \mathrm{C}$, respectively $[21,22]$.

Due to the inherent vulnerability of FBG, appropriate packaging methods are needed to make the bare FBG sensors applicable to engineering monitoring. The encapsulated FBG sensors should be calibrated because any protection technique may affect the strain transfer efficiency from the fiber surface to the inner core. The strain sensitivity of encapsulated FBG strain sensors is $0.60 \mathrm{pm} / \mu \varepsilon$ to $1.14 \mathrm{pm} / \mu \varepsilon$, and the temperature sensitivity is $10.39 \mathrm{pm} /{ }^{\circ} \mathrm{C}$ to $16.98 \mathrm{pm} /{ }^{\circ} \mathrm{C}$. The temperature sensitivity of packaged FBG temperature sensors is $5.25 \mathrm{pm} /{ }^{\circ} \mathrm{C}$ to $7.75 \mathrm{pm} /{ }^{\circ} \mathrm{C}$. Normally, the fiber Bragg grating is an isotropic cylinder structure, which will be subject to stresses in every direction. When the optic fiber is subject to tensile or compressive stress, both axial strain and lateral strain will be generated.
The refractive index of the material will change when a light wave passes through this medium, which will then affect the transmission characteristics. The lateral strain coefficient is about 0.0133 times the axial strain for Bragg gratings. Therefore, it is reasonable to only consider the optic-elastic effect in the axial direction [23]. With the change of temperature, the optic fiber expands with heat and contracts with cold, causing the diameter of the optic fiber to change. However, this change in diameter has a very small effect on the overall wavelength shift [20]. While the surface and the ground strata do present a temperature change during the lowering and grouting processes, this temperature change is less than $10^{\circ} \mathrm{C}$. Thus, the strain on the fiber Bragg gratings is considered to be the main cause of the wavelength shift experienced during installation.

The dead load of the FBG system, including the steel wire rope, was measured to be about $92.50 \mathrm{~kg}$. Neglecting the influence of temperature, the axial load on the FBG sensor is obtained by using the following equation:

$$
F=\varepsilon E S=\frac{\Delta \lambda_{B}}{K_{B, \varepsilon}} E \pi \frac{d^{2}}{4}
$$

where $F$ is the axial load of the FBG sensor, $E$ is Young's 


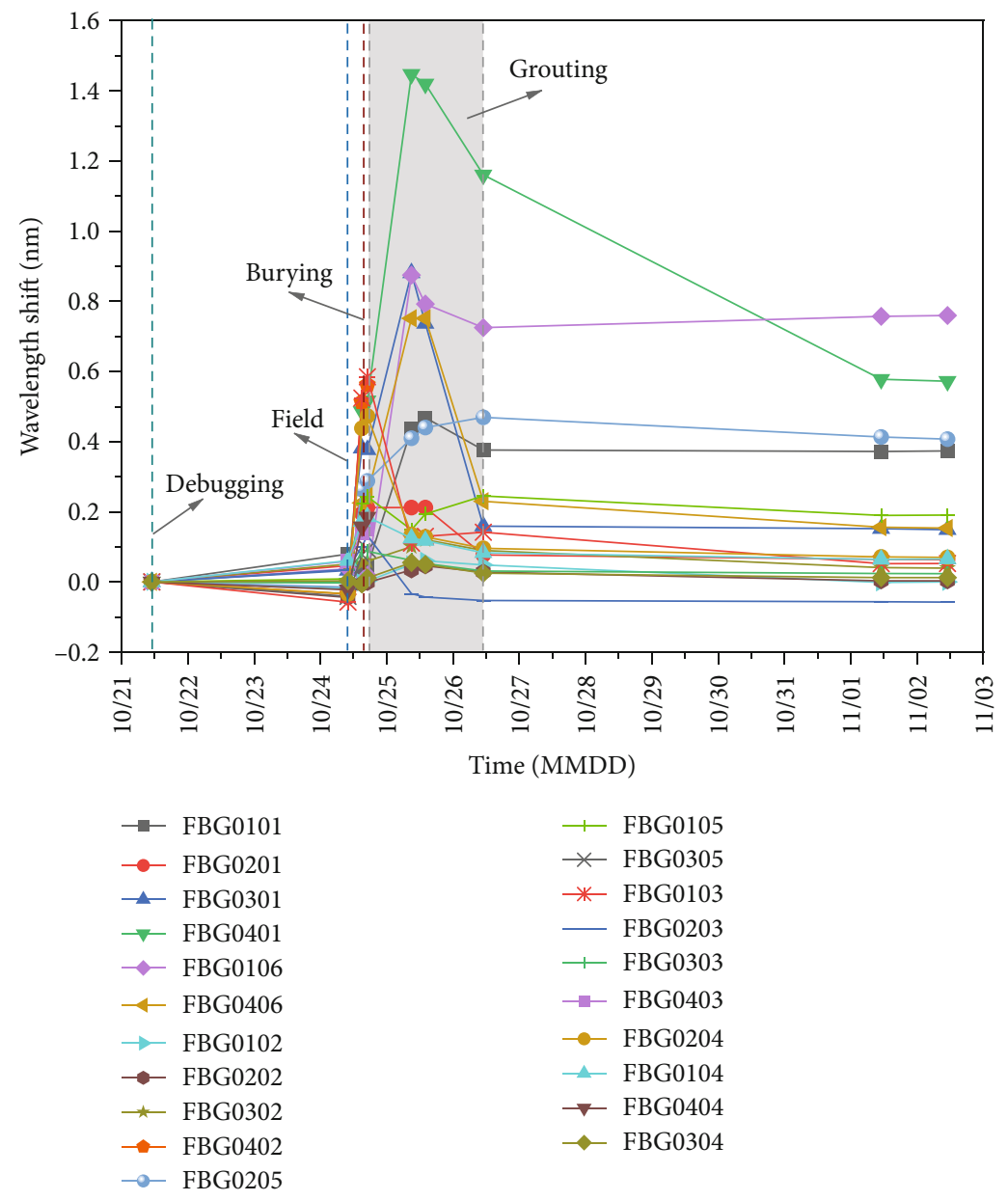

FIGURE 5: Central wavelength shift of the FBG sensor in the process of installation.

modulus, $S$ is the cross-sectional area of the FBG sensor, and $d$ is the diameter of the FBG sensor.

During installation, just as the assembly was beginning to be lowered into the borehole, the wavelength shift for FBG0401 was $0.486 \mathrm{~nm}$. According to equations (2) and (5), the axial strain of FBG0401 is $469.53 \mu \varepsilon$ and the axial tensile load was $51.72 \mathrm{~kg}$. As the installation of the assembly continued throughout the grouting stage, the wavelength shift for FBG0401 reached a maximum value of $1.447 \mathrm{~nm}$ with an axial strain of $1398.09 \mu \varepsilon$ and an axial load of $154.00 \mathrm{~kg}$, representing 1.66 of the system's dead load. Once installation of the system was complete and the system was able to stabilize, the stabilized wavelength shift was $0.574 \mathrm{~nm}$ with an axial strain of $554.51 \mu \varepsilon$ and an axial load of $61.08 \mathrm{~kg}$.

The results of field monitoring show, as expected, that the wavelength shift increases as the FBG sensor is subjected to increasing tensile stress. In addition, the farther away the FBG sensors are located from the bottom of the assembly, the larger the tensile stress that is experienced, in particular when compared to the lowest sensor on the assembly FBG0304. This particular behavior when lowering the FBG sensor assembly corresponds well with the general principles recognized for the mechanics of materials. Cable ties are used to attach the steel wire rope and the FBG system together. When the FBG system is well secured to the steel wire rope, the FBG system's dead load will transfer to the steel wire rope. Otherwise, if the FBG system is not securely attached, the dead load will be carried by both the steel wire rope and the FBG system. Under this later situation, the optic fiber cable may experience very large instantaneous loads and can thus break at weaker points along the system. Thus, it is important to protect the welded connecting points, the joints of the sensors, and the cable, by making sure that the load at these weak points can be transferred to the steel wire rope by effectively securing the FBG system to the steel wire rope.

The results of the real-time monitoring were able to allow us to identify that the failures of the FBG sensors occurred during the process of the second grouting step. The direction of force on the FBG sensor can be determined according to the wavelength shift of the FBG sensors during installation, as shown in Figure 9. During the second grouting process, the loose stratum in the range of 123.30 137.89 $\mathrm{m}$ appears to be the concentrated area of tensile stress and compressive stress. Under the influence of grouting, the wavelength shift of FBG0205 buried at $126.25 \mathrm{~m}$ depth increases gradually, the maximum 


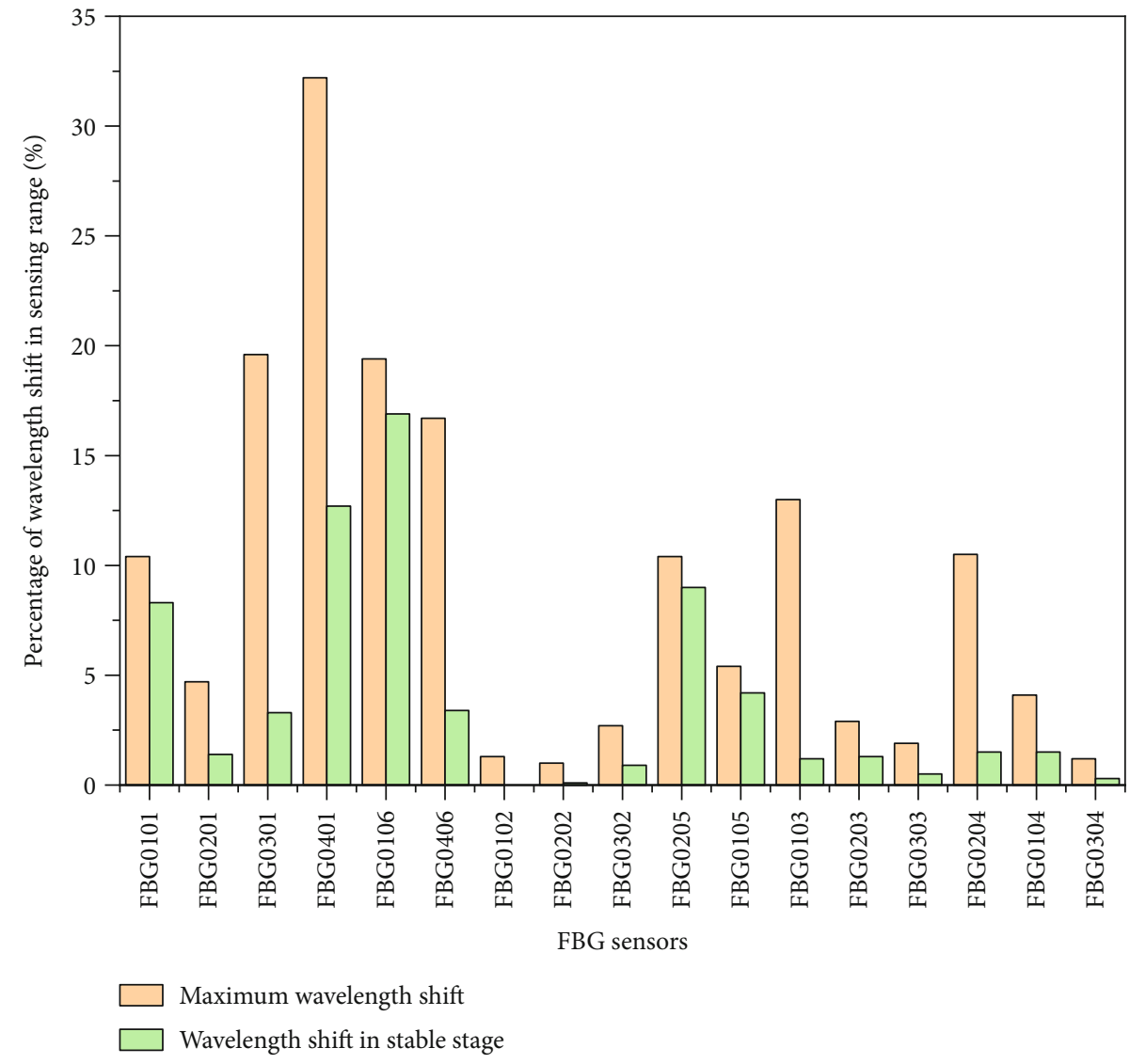

FIgURe 6: Percentage of wavelength shift in sensing range.

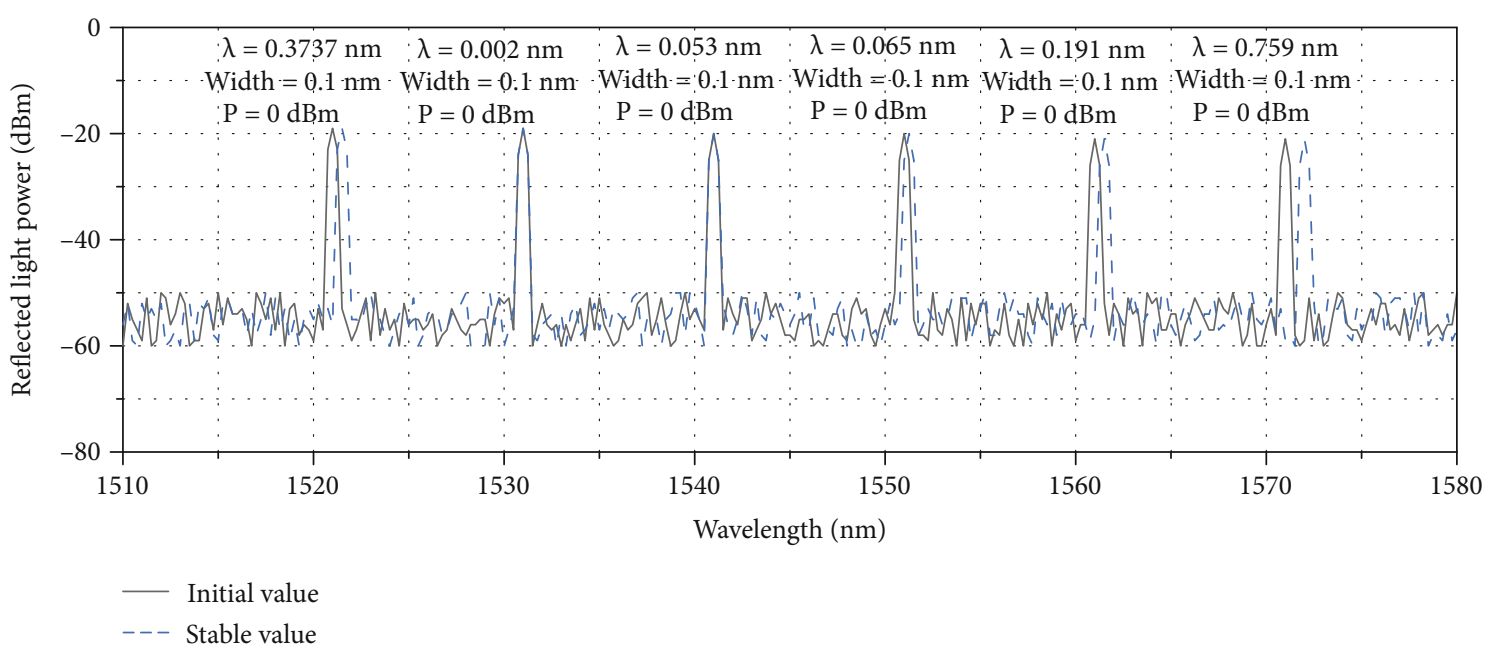

FIGURE 7: Reflection spectrum of the FBG sensors in the route I fiber loop on the optical fiber linear array.

wavelength shift is $0.2049 \mathrm{~nm}$, and the corresponding sensor strain is $192.47 \mu \varepsilon$. At the same time, the wavelength shift of FBG0103 under tensile stress with a buried depth of $137.89 \mathrm{~m}$ decreases gradually. The minimum wavelength shift value of FBG0103 is $-0.4716 \mathrm{~nm}$, and the corresponding strain value is $518.42 \mu \varepsilon$, which is the minimum value in the process of optical fiber system installation and can be used as the warning value of fiber optic cable fracture during the installation of the FBG monitoring system. Actually, the steel wire rope protection demonstrates to be effective in minimizing the cable breakage, and the field test is then significant to demonstrate the feasibility of monitoring the strata subsidence by using boreholeembedded FBG sensors, provided that the welded connecting points, the joints of the sensors, and the cable are appropriately protected. 


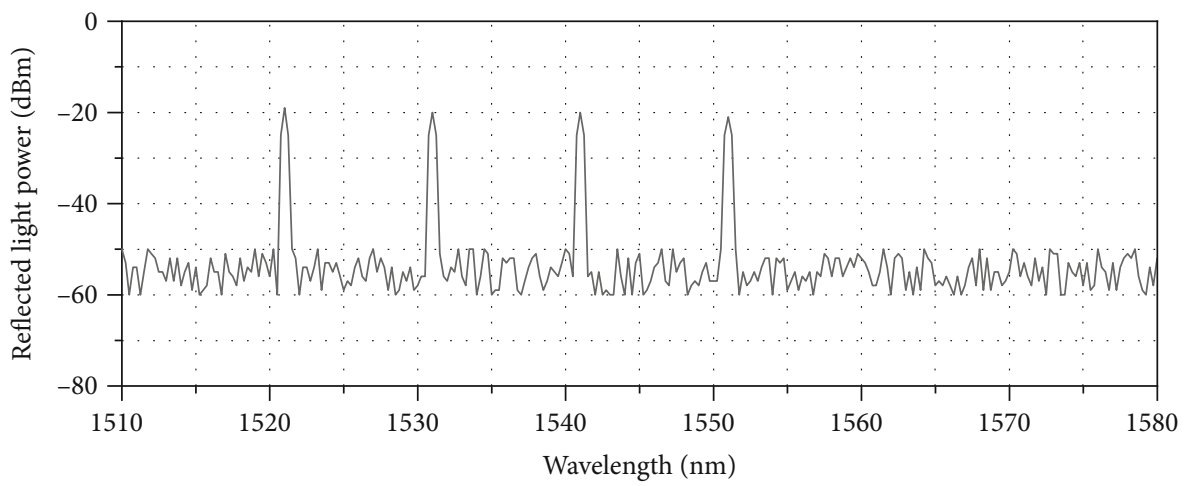

(a)

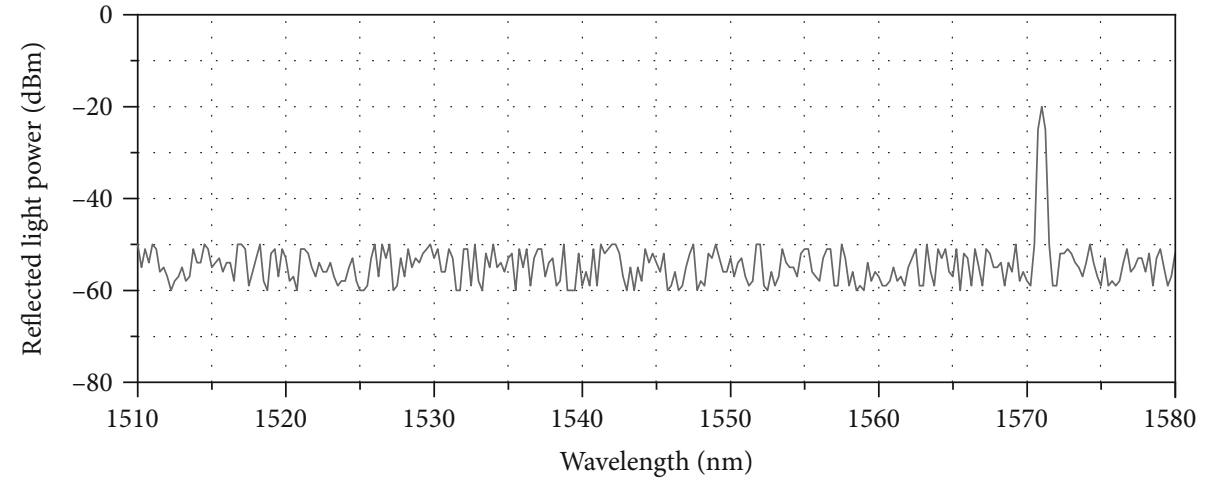

(b)

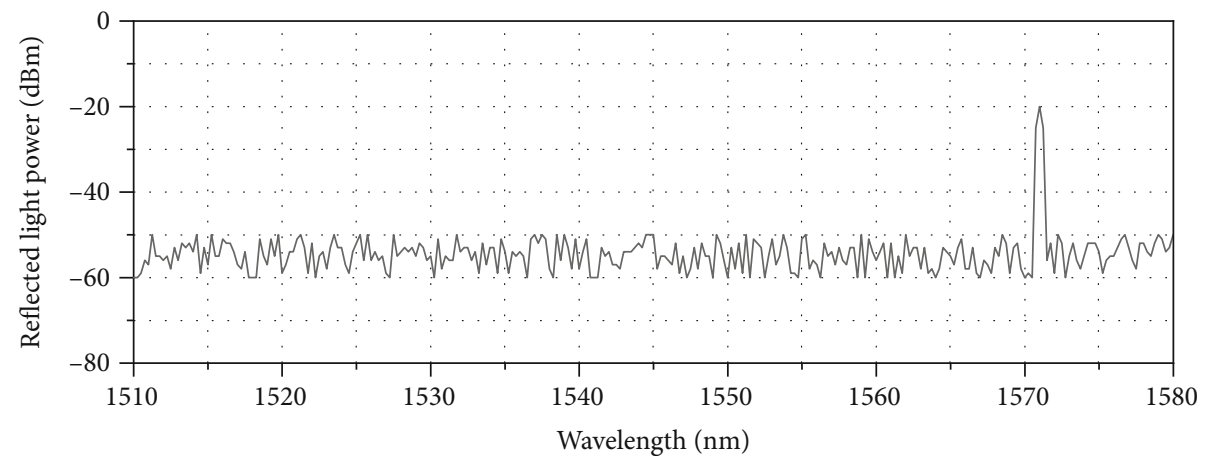

(c)

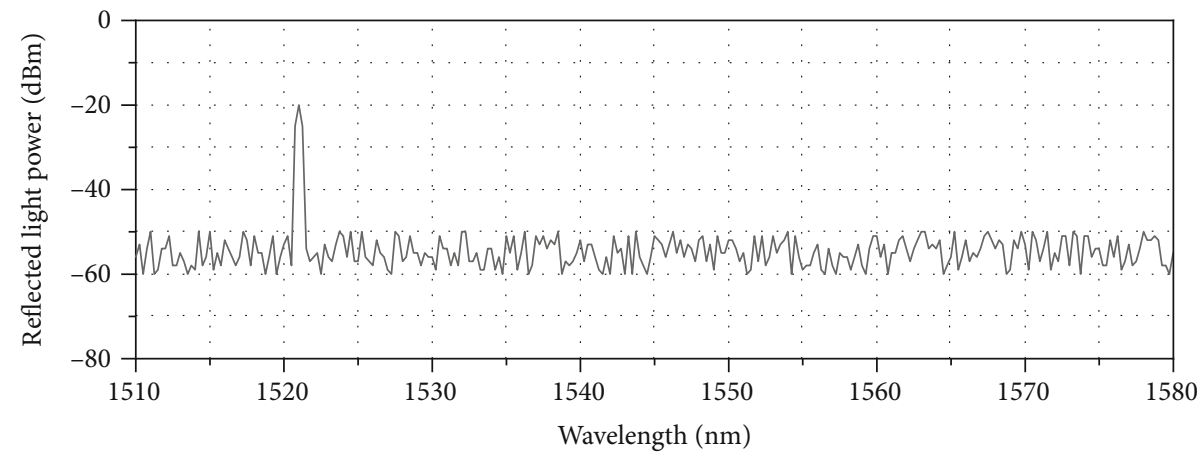

(d)

FIGURE 8: Reflection spectra of the FBG sensors on the optical fiber linear array: (a) channel 3 in route III; (b) channel 7 in route III; (c) channel 4 in route IV; (d) channel 8 in route IV. 


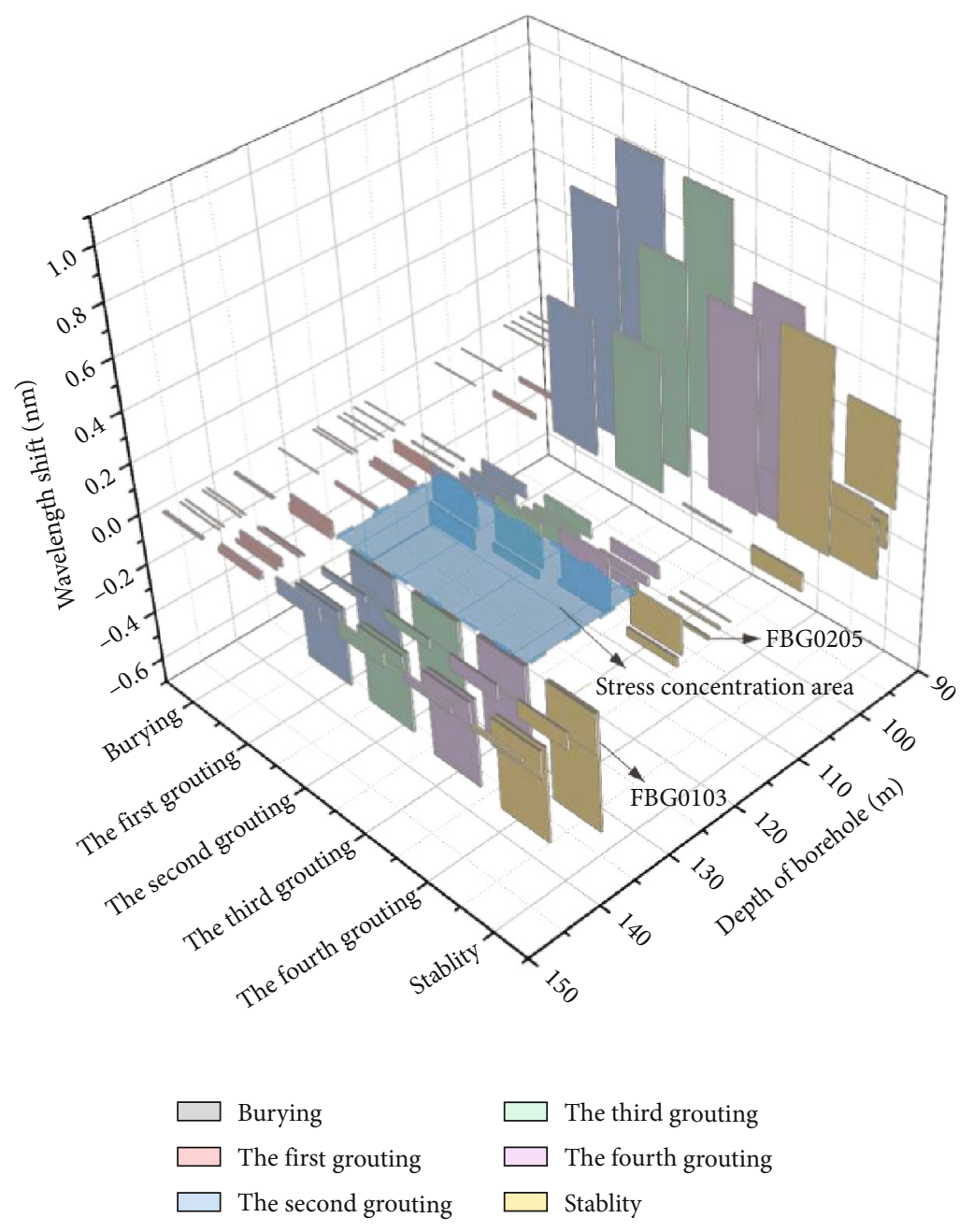

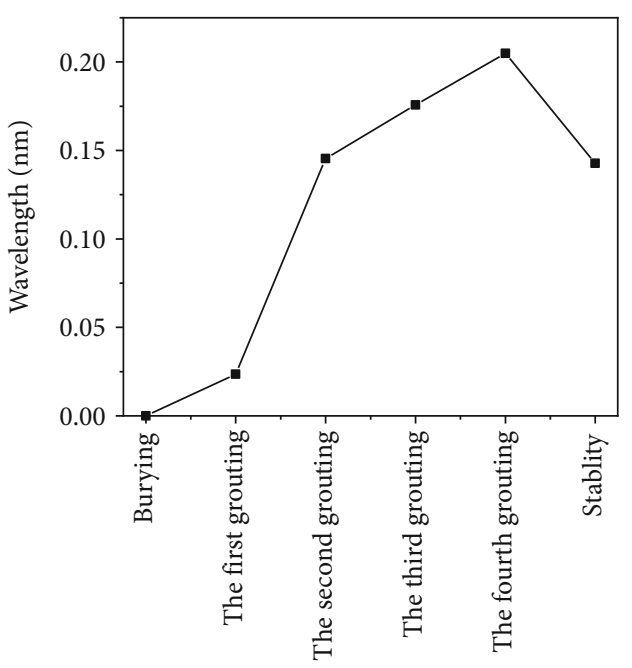

Birehole grouting progress

-- FBG0205

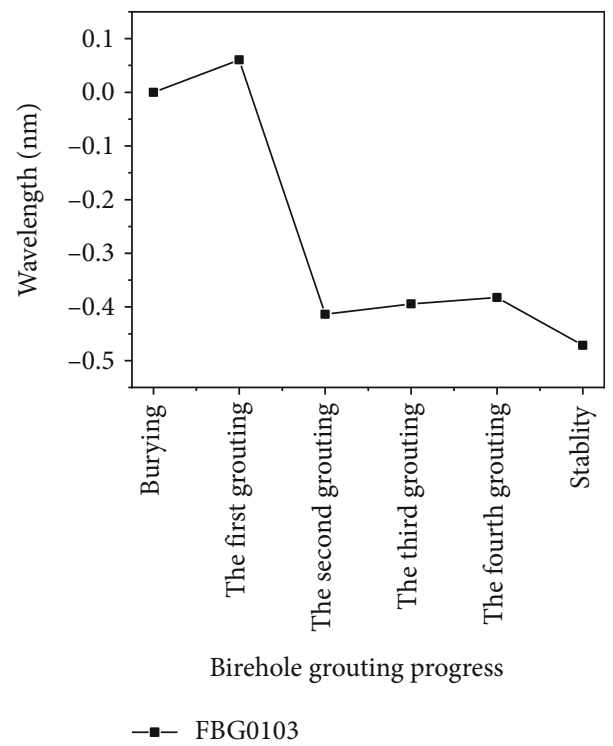

FIGURE 9: Force analysis of the fiber Bragg grating sensor during installation: (a) FBG0205; (b) FBG0103.

\section{Conclusions}

The installation process for the FBG ground strata-layered subsidence monitoring method described in this paper was found to have an effect on the wavelength of FBG sensors.

(1) The maximum axial strain that occurred was $1398.09 \mu \varepsilon$, and the corresponding wavelength shift was $1.447 \mathrm{~nm}$, which corresponded to about $16.82 \%$ of the wavelength detection range. Thus, it is necessary that the FBG sensor wavelength detection range be carefully considered, and after installation and stabilization are achieved, the initial central wavelength of the FBG sensor is adjusted to account for the shift that occurs
(2) The operation of lowering the FBG sensor system and the grouting process influence the mechanical and wavelength transmission characteristics of the system, which includes the introduction of high instantaneous loads that can damage the system. When the wavelength shift reaches $-0.4716 \mathrm{~nm}$ and the strain reaches $518.42 \mu \varepsilon$, we should be alert to the potential fracture risk of the optical cable

(3) Protecting the welded points and the joints of FBG sensors and optical fibers during installation is very important to the success of the system. The success rate for this particular field installation of a FBG monitoring system was $78.26 \%$, which was considered to be an improvement over what might have 
otherwise been achieved because of the "double channel" design that was used

(4) The FBG sensors located at shallower depths within the borehole typically exhibited a greater wavelength shift than the FBG sensors that were located deeper within the borehole. In order to improve the survival rate of the fiber Bragg grating sensor, the continuity of grouting in the borehole should be ensured as far as possible during the installation of the fiber Bragg grating sensor implanted in the borehole, and the tensile and compressive stress concentration area in the borehole due to the difference of slurry solidification time should be avoided

\section{Data Availability}

The data used to support the findings of this study are available from the corresponding author upon request.

\section{Conflicts of Interest}

The authors declare that they have no conflicts of interest.

\section{Acknowledgments}

The authors gratefully acknowledge the support provided to this project from the Special Fund for Basic Research on Scientific Instruments of the National Natural Science Foundation of China (41027002), the National Natural Science Foundation of PRC (51804244), and the Natural Science Foundation of Shaanxi Province Education Department (16JK1488).

\section{References}

[1] N. Basumallick, S. Bhattacharya, T. K. Dey, P. Biswas, and S. Bandyopadhyay, "Wideband fiber Bragg grating accelerometer suitable for health monitoring of electrical machines," IEEE Sensors Journal, vol. 20, no. 24, pp. 14865-14872, 2020.

[2] D. Kinet, P. Megret, K. W. Goossen, L. Qiu, D. Heider, and C. Caucheteur, "Fiber Bragg grating sensors toward structural health monitoring in composite materials: challenges and solutions," Shock and Vibration, vol. 14, no. 24, 7419 pages, 2014.

[3] A. A. Ikiades, "Strain measurement on cracks using fiber Bragg gratings for use in aircraft composite skin repairs," Aerospace, vol. 7, no. 9, p. 138, 2020.

[4] S. C. Her and W. N. Lin, "Simultaneous measurement of temperature and mechanical strain using a fiber Bragg grating sensor," Sensors, vol. 20, no. 15, p. 4223, 2020.

[5] J. Chai, Q. Liu, J. X. Liu, and D. D. Zhang, "Optical fiber sensors based on novel polyimide for humidity monitoring of building materials," Optical Fiber Technology, vol. 41, pp. 4047, 2018

[6] H. Liu, D. Liang, J. Zeng, J. Jin, J. Wu, and J. Geng, "Long period fiber grating refractive index sensitivity-based reinforcing rebar corrosion sensor in concrete," Acta Optica Sinica, vol. 31, no. 8, pp. 0806009-0806085, 2011.
[7] C. D. Piao, D. Wang, H. Kang, H. He, C. Q. Zhao, and W. Y. Liu, "Model test study on overburden settlement law in coal seam backfill mining based on fiber Bragg grating technology," Arabian Journal of Geosciences, vol. 12, no. 13, pp. 1-9, 2019.

[8] D. D. Zhang, J. Chai, Y. Li, and Y. Y. Sun, "Strain transfer function of embedded fiber Bragg grating sensors for unconsolidated layer settlement deformation detector and its application," Chinese Journal of Rock Mechanics and Engineering, vol. 34, pp. 3289-3297, 2015.

[9] D. S. Xu, H. B. Liu, and W. L. Luo, "Evaluation of interface shear behavior of GFRP soil nails with a strain- transfer model and distributed fiber-optic sensors," Computers and Geotechnics, vol. 95, pp. 180-190, 2018.

[10] C. Holmes, M. Godfrey, D. J. Bull, and J. Dulieu-Barton, "Realtime through-thickness and in-plane strain measurement in carbon fibre reinforced polymer composites using planar optical Bragg gratings," Optics and Lasers in Engineering, vol. 133, p. 106111, 2020.

[11] G. Cui, "Failure mechanism of vertical shaft wall and control techniques in special formation condition," Mine Construction Technology, vol. 1998, no. 2, pp. 28-32, 1998.

[12] K. Gu, B. Shi, C. Liu, H. T. Jiang, T. B. Li, and J. H. Wu, "Investigation of land subsidence with the combination of distributed fiber optic sensing techniques and microstructure analysis of soils," Engineering Geology, vol. 240, pp. 34-47, 2018.

[13] J. H. Wang, L. Jiang, Z. G. Sun et al., "Research on the surface subsidence monitoring technology based on fiber Bragg grating sensing," Photonic Sensors, vol. 7, no. 1, pp. 20-26, 2017.

[14] J. Chai, J. X. Liu, B. Qiu et al., "Detecting deformations in uncompacted strata by fiber Bragg grating sensors incorporated into GFRP," Tunnelling and Underground Space Technology, vol. 26, no. 1, pp. 92-99, 2011.

[15] C. A. Brackett, "Dense wavelength division multiplexing networks - principles and applications," IEEE Journal on Selected Areas in Communications, vol. 8, no. 6, pp. 948-964, 1990.

[16] L. J. He, S. B. Hu, and W. C. Yang, "Temperature measurement in the main hole of the Chinese Continental Scientific Drilling," Chinese Journal of Geophysics, vol. 49, no. 3, pp. 671678, 2006.

[17] J. Chai, L. Zhu, D. D. Zhang et al., "Study on settlement deformation of unconsolidated strata during low-pressure water injection process of multi-borehole," Journal of the China Coal Society, vol. 38, no. 10, pp. 1720-1727, 2013.

[18] H. Y. Ling, K. T. Lau, W. Jin, and K. C. Chan, "Characterization of dynamic strain measurement using reflection spectrum from a fiber Bragg grating," Optics Communications, vol. 270, no. 1, pp. 25-30, 2007.

[19] K. Peters, P. Pattis, J. Botsis, and P. Giaccari, "Experimental verification of response of embedded optical fiber Bragg grating sensors in non-homogeneous strain fields," Optics and Lasers in Engineering, vol. 33, no. 2, pp. 107-119, 2000.

[20] A. G. Leal-Junior, A. Theodosiou, C. R. Diaz et al., "Simultaneous measurement of axial strain, bending and torsion with a single fiber Bragg grating in CYTOP fiber," Journal of Lightwave Technology, vol. 37, no. 3, pp. 971-980, 2019.

[21] A. D. Kersey, M. A. Davis, H. J. Patrick et al., "Fiber grating sensors," Journal of Lightwave Technology, vol. 15, no. 8, pp. 1442-1463, 1997. 
[22] T. H. T. Chan, L. Yu, H. Y. Tam et al., "Fiber Bragg grating sensors for structural health monitoring of Tsing Ma bridge: background and experimental observation," Engineering Structures, vol. 28, no. 5, pp. 648-659, 2006.

[23] H. Garcia-Miquel, D. Barrera, R. Amat, G. V. Kurlyandskaya, and S. Sales, "Magnetic actuator based on giant magnetostrictive material Terfenol-D with strain and temperature monitoring using FBG optical sensor," Measurement, vol. 80, pp. 201206, 2016. 